\title{
THE APPLICABILITY OF THE 40 TRIZ PRINCIPLES IN DESIGN FOR ADDITIVE MANUFACTURING
}

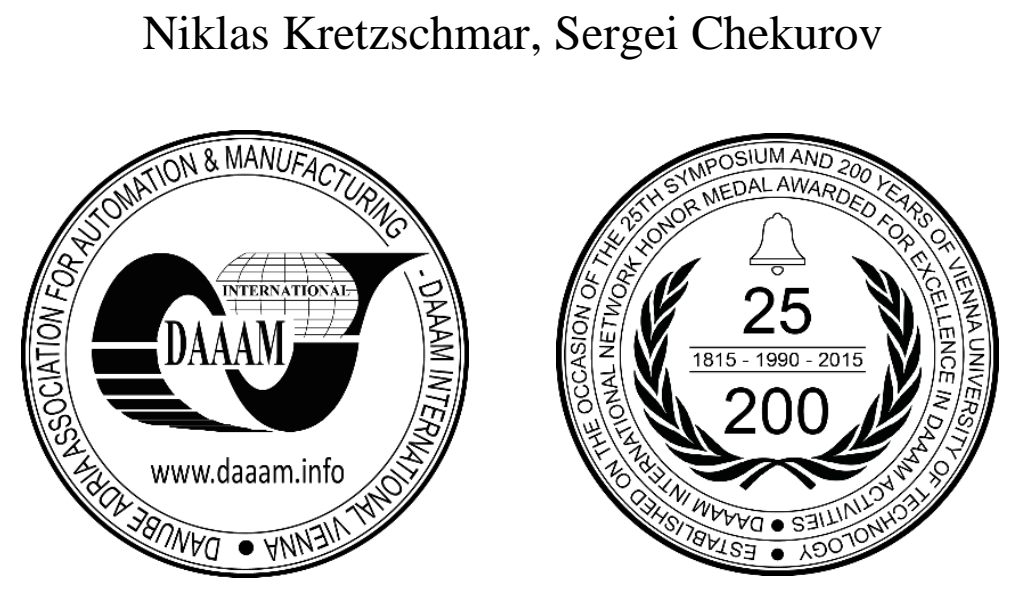

This Publication has to be referred as: Kretzschmar, N[iklas] \& Chekurov, S[ergei] (2018). The Applicability of the 40 TRIZ Principles in Design for Additive Manufacturing, Proceedings of the 29th DAAAM International Symposium, pp.0888-0893, B. Katalinic (Ed.), Published by DAAAM International, ISBN 978-3-902734-20-4, ISSN 1726-9679, Vienna, Austria

DOI: $10.2507 / 29$ th.daaam.proceedings.128

\begin{abstract}
The theory of inventive problem solving methodology (TRIZ) is a well-established accelerator to support problem solving by linking specific engineering problems and solutions to general patterns. TRIZ can be applied in conjunction with Design for Additive Manufacturing (DFAM) to create novel geometries, shapes, and enhanced functionalities. In this study, the applicability for DFAM of each of the 40 inventive principles of TRIZ is evaluated and classified. Examples for three TRIZ principles (i.e. asymmetry, nested doll, blessing in disguise) are evaluated further in the context of DFAM, outlining their advantages in functionality and performance. This study is particularly helpful to practitioners who are unfamiliar with the concept of DFAM.
\end{abstract}

Keywords: design for additive manufacturing; TRIZ; 40 inventive principles; principle mapping; laser-beam based additive manufacturing

\section{Introduction}

Genrich Altshuller developed a constructive methodology for innovation, the theory of inventive problem solving (TRIZ), which is an acronym from its Russian title, in 1956.

\subsection{Background}

The methodology encompasses the input of more than 2 million patents to map specific problems to specific solutions derived from interposing typical problems and solutions. The algorithm of problem solving begins with the modeling of the specific problem by defining contradictions. In the next step called extracting, transformations from previously solved problems consisting of the 40 TRIZ principles are conducted to define the general problem [1]. Through the identification of analogies to a general solution, a specific solution can be found by applying an analogous solution. This innovationseeking methodology was successfully applied in numerous international companies (e.g. Samsung and IBM) and in public research [2], [3]. 
TRIZ is being used in many fields of expertise until today; for instance, an example case from the field of engineering is a gripping system to handle objects, supported by embedded sensors. To improve its functionality, the 39 engineering parameters of TRIZ were evaluated for implementation to design this application. A molding tool was created and filled with silicone rubber to generate the component. In a post-processing step, the final component was press-cured [4]. Applying Additive Manufacturing (AM) processes for the production of the gripping system could have been beneficial (complex shape, low batch volume), eliminating the need for molding.

\subsection{TRIZ in the context of AM}

Within the context of AM, there have been successful attempts to apply the TRIZ methodology, for example, in the case of an external reamer which is designed in a biomimetic approach to optimize part specific aspects (i.e. mass, volume and surface) as well as process and part performance relevant parameters. The component was specifically designed to gain from the advantages of AM [5]. Design for Additive Manufacturing (DFAM), a collective term that encompasses several design methods, takes advantage of the layer-wise production process of AM to create novel geometries, shapes, and enhanced functionalities [6]. Some of the inventive principles are already integral elements in the practice of DFAM, while others warrant more research to find applications. However, there are only a few examples in which the TRIZ methodology is applied purposely to solve AM-related issues. A large number of TRIZ's innovative principles have been applied in AM unknowingly. In this theoretical study, 40 AM examples, which fit into the context of the 40 principles of TRIZ without initially considering the connection to it, are presented.

\section{Methods and results}

As shown in Figure 1, the classification scheme consists of two steps. In the first step, each AM example is classified into one or several categories, consisting of DFAM, LAM (Laser-beam based Additive Manufacturing) and AMPC (Additive Manufacturing process characteristic). In this classification, LAM comprises Selective Laser Sintering (SLS), Selective Laser Melting (SLM), Laser Engineered Net Shaping (LENS), and Stereolithography (SL), which all have the same process characteristic in common: fusing or curing material with a laser. The following definitions are considered:

- DFAM: the example is highly relevant for the design process when applying AM as a selected production method

- LAM: the example shows specific relevance for laser-beam based additive manufacturing processes

- AMPC: the example implies a process-relevant characteristic of an existing additive manufacturing process

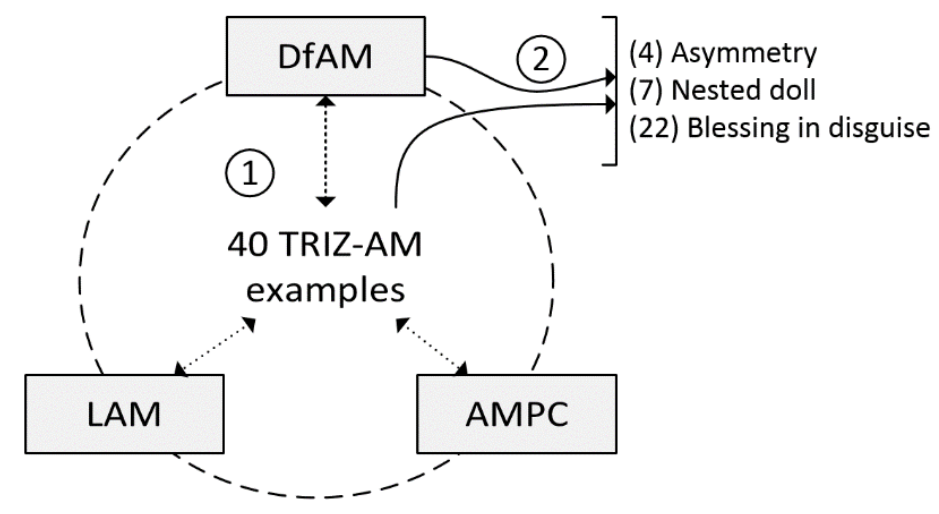

Fig. 1. Classification scheme of TRIZ-related AM examples

In the second step, DFAM-relevant examples are presented in detail, linked to existing literature and evaluated according to their underlying potential.

\subsection{AM applying TRIZ}

According to Table 1, at least one AM example was mapped to each of the 40 TRIZ principles, fitting into at least one of the three definitions.

For instance, DFAM is applied in (3) to change the local quality (modifying object's structure from uniform to nonuniform) by using lattice structures. DFAM is also used to address TRIZ principle (14), the spheroidality-curvature, by topology optimization, using curvilinear surfaces, and forms instead of rectilinear ones. Examples related to LAM are described by (26), prototyping, which involves making copies of components in a simple and inexpensive way with, for instance, SL. Mechanical vibration (18) is considered relevant for the support removal with vibration, which is a common process step in SLM and SLS after the objects are printed. 


\begin{tabular}{|c|c|c|c|c|c|}
\hline \# & TRIZ principle & AM example & $\begin{array}{r}\text { Cla } \\
\text { DFAM }\end{array}$ & $\begin{array}{l}\text { Issificat } \\
\text { LAM }\end{array}$ & $\begin{array}{l}\text { tion } \\
\text { AMPC }\end{array}$ \\
\hline 1 & Segmentation & Divide a component into smaller pieces in CAD & & $\mathrm{x}$ & \\
\hline 2 & Taking out & $\begin{array}{l}\text { Take an essential part out of the component and apply } \\
\text { AM }\end{array}$ & & $\mathrm{x}$ & \\
\hline 3 & Local quality & The use of lattice structures & $\mathrm{x}$ & $\mathrm{x}$ & \\
\hline 4 & Asymmetry & A channel that changes its cross-sectional area & $\mathrm{x}$ & $\mathrm{x}$ & \\
\hline 5 & Merging & $\begin{array}{l}\text { A mechanism that works directly after printing } \\
\text { without assembly }\end{array}$ & $\mathrm{x}$ & $\mathrm{x}$ & \\
\hline 6 & Universality & $\begin{array}{l}\text { Faster production times when objects are merged (e.g. } \\
\text { air ducts) }\end{array}$ & $\mathrm{x}$ & $\mathrm{x}$ & \\
\hline 7 & Nested doll & Designs that can be printed collapsed (e.g. chain) & $\mathrm{x}$ & $\mathrm{x}$ & \\
\hline 8 & Anti-weight & $\begin{array}{l}\text { Hollow (or lattice structure filled) components in } \\
\text { airplanes }\end{array}$ & $\mathrm{x}$ & $\mathrm{x}$ & \\
\hline 9 & Preliminary anti-action & $\begin{array}{l}\text { 3D-printable acoustic insulation (specific tower } \\
\text { pattern) }\end{array}$ & $\mathrm{x}$ & $\mathrm{x}$ & \\
\hline 10 & Preliminary action & $\begin{array}{l}\text { Design object in a way that it can be post-processed } \\
\text { easily }\end{array}$ & & $\mathrm{x}$ & \\
\hline 11 & Beforehand cushioning & $\begin{array}{l}\text { Design holes to remove powder of inner functions } \\
\text { after the print }\end{array}$ & & $\mathrm{x}$ & $\mathrm{x}$ \\
\hline 12 & Equipotentiality & Flexible objects produced with AM & & & $\mathrm{x}$ \\
\hline 13 & The other way around & Comparison of SL and DLP build platform movement & & $\mathrm{x}$ & $\mathrm{x}$ \\
\hline 14 & Spheroidality - Curvature & Topology optimization & $\mathrm{x}$ & $\mathrm{x}$ & \\
\hline 15 & Dynamics & Customization of design & $\mathrm{x}$ & $\mathrm{x}$ & \\
\hline 16 & Partial or excessive actions & $\begin{array}{l}\text { Design for steeper angles than instructed when } \\
\text { possible }\end{array}$ & $\mathrm{x}$ & $\mathrm{x}$ & \\
\hline 17 & Another dimension & Applying 4D Printing & $\mathrm{x}$ & & $\mathrm{x}$ \\
\hline 18 & Mechanical vibration & Support removal with vibration & & $\mathrm{x}$ & $\mathrm{x}$ \\
\hline 19 & Periodic action & $\begin{array}{l}\text { Oxygen-permeable layer allows continuous printing } \\
\text { with CLIP }\end{array}$ & & & $\mathrm{x}$ \\
\hline 20 & Continuity of useful action & $\begin{array}{l}\text { Adding new powder from both sides of the build } \\
\text { chamber }\end{array}$ & & $\mathrm{x}$ & $\mathrm{x}$ \\
\hline 21 & Skipping & High laser speed to avoid melt pool sputter & & $\mathrm{x}$ & $\mathrm{x}$ \\
\hline 22 & Blessing in disguise & Benefit from rough surfaces (e.g. heat exchanger) & $\mathrm{x}$ & $\mathrm{x}$ & \\
\hline 23 & Feedback & Closed loop for heat control in SLM & & $\mathrm{x}$ & $\mathrm{x}$ \\
\hline 24 & Intermediary & Removable build plate in SLM & & $\mathrm{x}$ & $\mathrm{x}$ \\
\hline 25 & Self-service & Re-use of metal powder & & $\mathrm{x}$ & $\mathrm{x}$ \\
\hline 26 & Copying & Prototyping & $\mathrm{x}$ & $\mathrm{x}$ & \\
\hline 27 & Cheap short-living objects & Emergency spare parts / home appliance replacements & & $\mathrm{x}$ & \\
\hline 28 & Mechanics substitution & $\begin{array}{l}\text { New ways of integrated identification of components } \\
\text { (imprints) }\end{array}$ & $\mathrm{x}$ & $\mathrm{x}$ & \\
\hline 29 & Pneumatics and hydraulics & Deformable grippers actuated with pneumatics & & $\mathrm{x}$ & \\
\hline 30 & $\begin{array}{l}\text { Flexible shells and thin } \\
\text { films }\end{array}$ & Basic printing mechanism of LOM & & & $\mathrm{x}$ \\
\hline 31 & Porous materials & Lattice structures / porous lubrication & $\mathrm{x}$ & $\mathrm{x}$ & \\
\hline 32 & Color changes & Photopolymer 3D printing & $\mathrm{x}$ & & $\mathrm{x}$ \\
\hline 33 & Homogeneity & LENS of turbine blades & $\mathrm{x}$ & $\mathrm{x}$ & $\mathrm{x}$ \\
\hline 34 & Discarding and recovering & Support dissolving (e.g. FDM) & & & $\mathrm{x}$ \\
\hline 35 & Parameter changes & Make solid parts from powder (m-PBF) & & $\mathrm{x}$ & $\mathrm{x}$ \\
\hline 36 & Phase transitions & Post-build sintering shrinkage (metal FDM) & $\mathrm{x}$ & & $\mathrm{x}$ \\
\hline 37 & Thermal expansion & Crucial process parameter to be controlled in $\mathrm{m}-\mathrm{PBF}$ & $\mathrm{x}$ & $\mathrm{x}$ & $\mathrm{x}$ \\
\hline 38 & Strong oxidants & As applied in the CLIP technology & & & $\mathrm{x}$ \\
\hline 39 & Inert atmosphere & Needed in the SLM process & & $\mathrm{x}$ & $\mathrm{x}$ \\
\hline 40 & Composite materials & Carbon fiber composite applied in FDM & & & $\mathrm{x}$ \\
\hline
\end{tabular}

Table 1. AM examples in the context of TRIZ principles 
A carbon fiber composite applied in the Fused Deposition Modeling (FDM) process fits into the scope of composite materials (40), a process-relevant AM characteristic, implying a change from uniform to composite materials. Another AMPC example is described by (30), applying flexible shells and thin films, a characteristic, which occurs in the Laminated Object Manufacturing (LOM) process. Interestingly, examples for TRIZ principles could be identified which match with all definitions for classification. Applying LENS for the repair of turbine blades makes an object interact with an existing object of the same material, which leads to homogeneity. The work principle of LENS results in specific design limitations (DFAM) and demands for high-laser powers (LAM) to satisfy process-relevant characteristics (AMPC).

\subsection{DFAM applying TRIZ}

To better illustrate the connection of TRIZ principles with advantages in AM, three of the principles are given examples that are described more detailed: Asymmetry (4), Blessing in disguise (22), and Nested doll (7).

The notion that components should be symmetric comes from the fact that it is easier in subtractive manufacturing to process several identical features on one component than to consider each feature separately. In AM, this is no longer the issue, as manufacturing a part with identical features no longer carries an explicit advantage. Therefore, topology optimization, heterogeneous lattices, and irregular cavities, among others, are features that are seeing implementations in real products [7] [8].

An example of the TRIZ principle of asymmetry is illustrated in Figure 2. In this high-pressure hydraulic valve system, the topology is optimized for stiffness by placing irregular cavities on the surface of the component. Connecting features such as inlets and outlets are flattened to allow suitable contacts for assembly. This component is ideally designed for metal Powder Bed Fusion (m-PBF) using stainless steel powders.

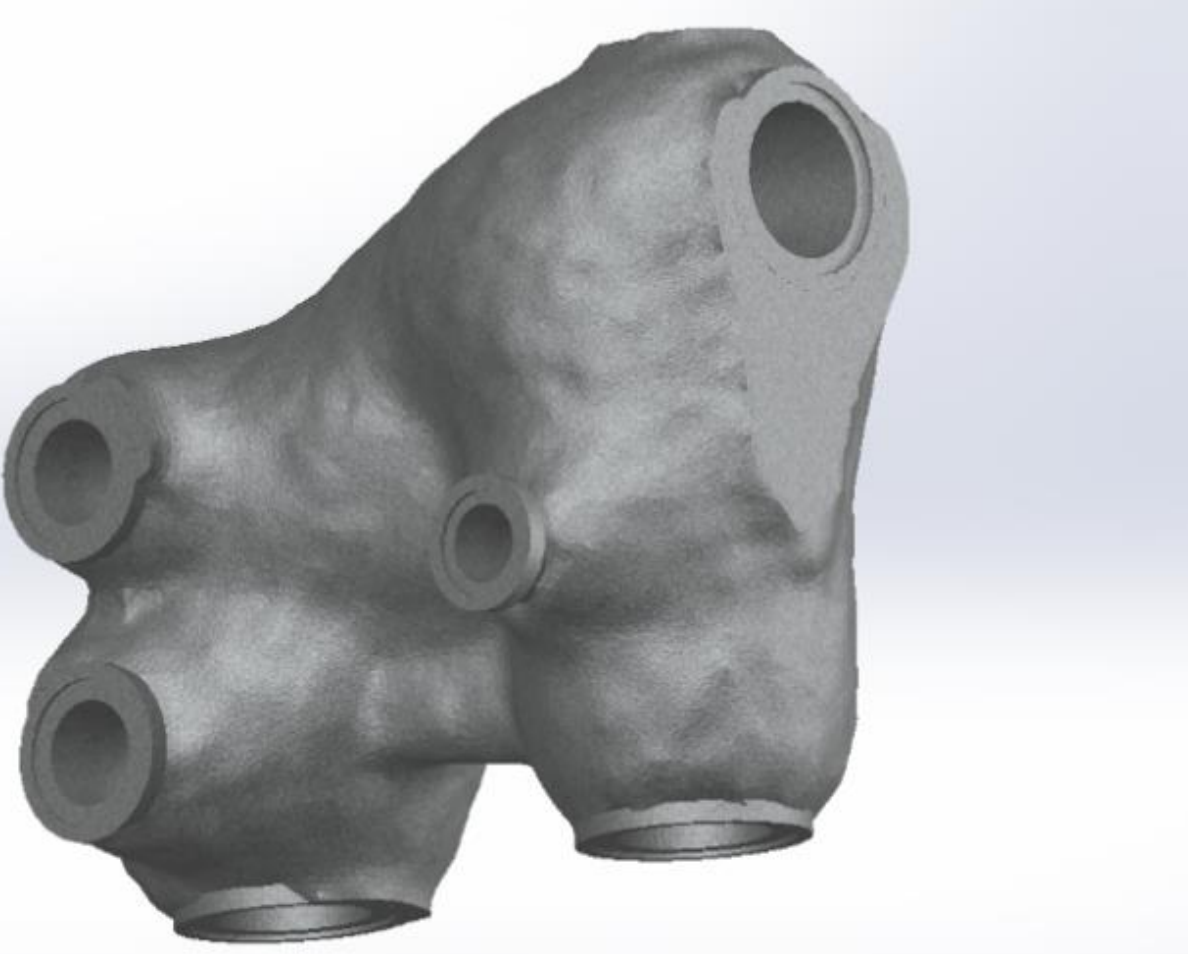

Fig. 2. High-pressure hydraulic valve system optimized for stiffness

When manufacturing parts with AM and especially with SLM, the surface roughness is often problematic in real world applications. As with other manufacturing technologies, parts produced with AM can be post-processed externally to achieve a sufficient surface quality for final products.

However, since a special strength of AM is the production of internal geometries, designers often lament that post processing them is impossible and thus the part cannot be used. Luckily, the otherwise insufficient surface roughness of AM can be implemented in applications that benefit from the increased surface area. One such application area is represented by heat exchangers, in which the high surface roughness of AM has an additional advantage of preventing the streams from becoming laminar, thus increasing the efficiency of the heat transfer [9], [10], [11]. An AM example for the significance of this TRIZ principle is presented in Figure 3. 


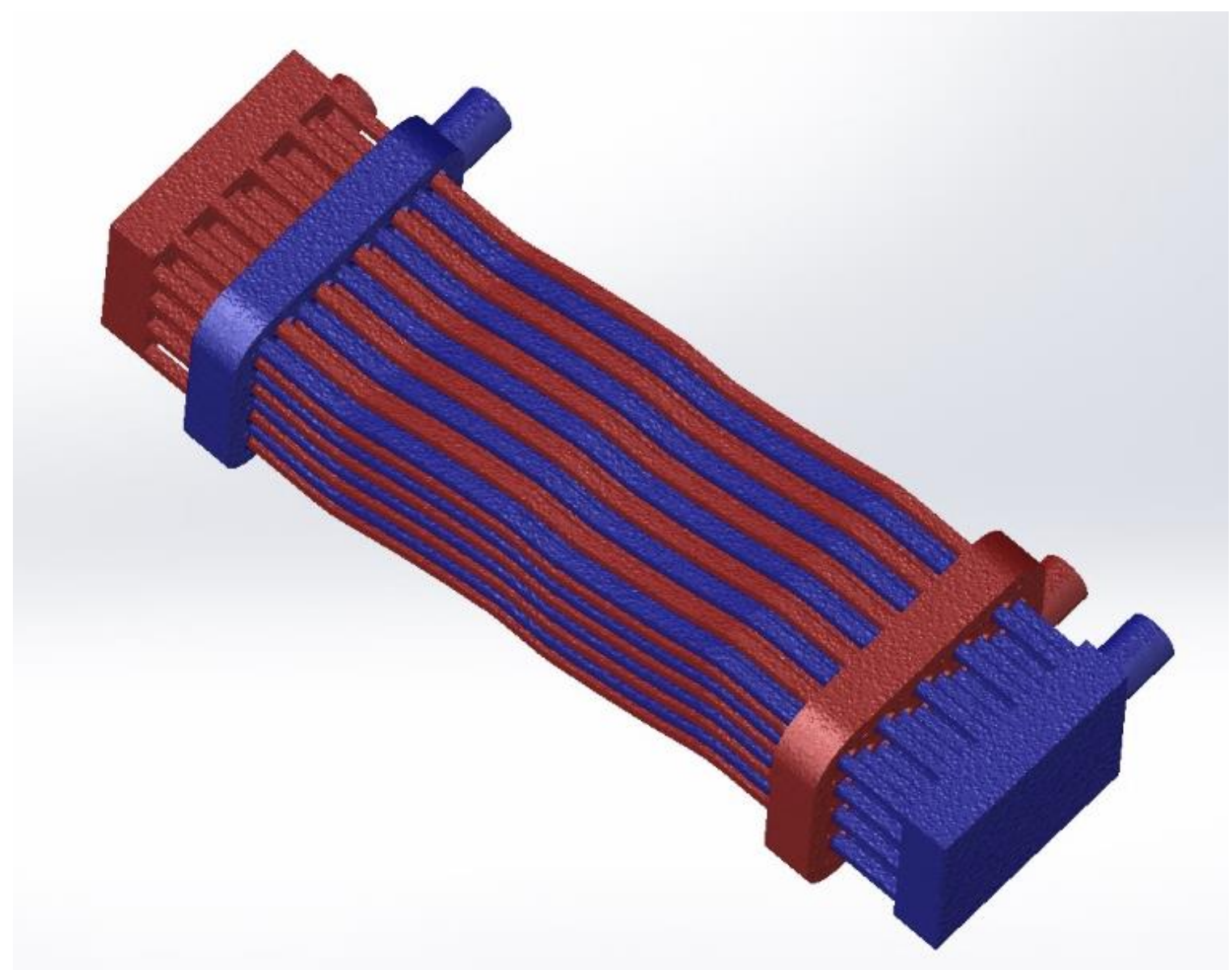

Fig. 3. Counter-flow heat exchanger profiting from increased surface area and high surface roughness

The nested doll principle is particularly interesting in the area of build preparation and assembly manufacturing in AM. Because the build volume of machines is still limited, it is beneficial to design parts in such a way that they can fit in a smaller space. Such designs could be flexible and collapsible on themselves, so that they can be printed flat and expanded into their final shape once the manufacturing process is over. An exciting development in this regard is that of 4D printing, which aims to produce parts whose shape can be modified after manufacturing.

Another approach to the nested doll principle in AM is the use of assemblies that are printed as one part, sometimes referred to as non-assemblies. Such designs could not only save space in a print envelope, but also add new functionalities to products [12], [13].

\section{Future work and limitations}

The list of examples (Table 1) gives an impression which AM examples fit within the scope of TRIZ. However, this list is brainstormed by the authors and can be expanded. Thus, the classification can also show different results for the same TRIZ principle. For the future, more research should focus on the methodical application of the TRIZ principles in DFAM to create advanced components and generate improved functionalities.

\section{Conclusions}

For each of the 40 TRIZ principles, at least one AM example could be identified and linked to the classification items (DFAM and/or LAM and/or AMPC). New development in AM such as 4D Printing, CLIP and carbon fiber composites applied in FDM can be traced back to a specific TRIZ principle, which is a sign for its today's relevance. For many of the principles, examples with a strong link to DFAM could be formulated, indicating that the TRIZ principles can be widely applied for design-related purposes today.

Three AM examples in the context of DFAM were presented in detail, showing that several TRIZ principles are already unknowingly applied in literature, implying advantages arising from the usage of AM. These advantages can be found for example in the asymmetry of inner channels, efficiency increases through rougher surfaces, and non-assemblies. However, there are not many scientific studies existent which consciously apply TRIZ principles for problem solving in DFAM. 


\section{References}

[1] Altshuller, G. S., Shulyak, L., \& Rodman, S. (1997). 40 Principles: TRIZ Keys to Technical Innovation. Technical Innovation Center, INC, 978-0964074033, Worcester, MA, United States

[2] Orloff, M. A. (2017). ABC-TRIZ_Introduction to Creative Design Thinking with Modern TRIZ Modeling, Springer International Publishing, 978-3-319-29435-3, Cham, Switzerland

[3] Chechurin, L., \& Borgianni, Y. (2016). Understanding TRIZ through the review of top cited publications. Computers in Industry, pp. 82, 119-134, https://doi.org/10.1016/j.compind.2016.06.002

[4] Petković, D., Issa, M., Pavlović, N. D., \& Zentner, L. (2013). Application of the TRIZ creativity enhancement approach to design of passively compliant robotic joint. International Journal of Advanced Manufacturing Technology, 67(1-4), pp. 865-875, https://doi.org/10.1007/s00170-012-4530-4

[5] Kamps, T., Münzberg, C., Stacheder, L., Seidel, C., Reinhart, G., \& Lindemann, U. (2015). TRIZ-based biomimetic part-design for Laser Additive Manufacturing. Lasers in Manufacturing Conference 2015. Munich, Germany

[6] Hanzl, Pavel; Zetkova, Ivana; Dana, M. (2017). A comparison of lattice structures in metal additive manufacturing. Proceedings of the 28th DAAAM International Symposium, pp. 0481-0485, https://doi.org/10.2507/28th.daaam.proceedings.067

[7] Orme, M. E., Gschweitl, M., Ferrari, M., Madera, I., \& Mouriaux, F. (2017). Designing for Additive Manufacturing: Lightweighting Through Topology Optimization Enables Lunar Spacecraft. Journal of Mechanical Design, 139(10), pp. 100905-100905-6. https://doi.org/10.1115/1.4037304

[8] Pietropaoli, M., Ahlfeld, R., Montomoli, F., Ciani, A., \& D’Ercole, M. (2016). Journal of Engineering for Gas Turbines and Power, 139(10), pp. 102101-102101-8, DOI:10.1115/1.4036358.

[9] Sam Huang, H., Varshney, V., Wohlwend, J. L., \& Roy, A. K. (2013). Heat Transfer at Aluminum-Water Interfaces: Effect of Surface Roughness. Journal of Nanotechnology in Engineering and Medicine, 3(3), pp. 031008-0310086, https://doi.org/10.1115/1.4007584

[10] Ventola, L., Chiavazzo, E., Calignano, F., Manfredi, D., \& Asinari, P. (2014). Heat transfer enhancement by finned heat sinks with micro-structured roughness. In Journal of Physics: Conference Series (Vol. 494), https://doi.org/10.1088/1742-6596/494/1/012009

[11] Achenbach, E. (1977). The effect of surface roughness on the heat transfer from a circular cylinder to the cross flow of air. International Journal of Heat and Mass Transfer, 20(4), pp. 359-369, https://doi.org/10.1016/00179310(77)90157-0

[12] Yang, S., Tang, Y., \& Zhao, Y. F. (2015). A new part consolidation method to embrace the design freedom of additive manufacturing. Journal of Manufacturing Processes, 20, pp. 444-449, https://doi.org/10.1016/j.jmapro.2015.06.024

[13] Rosen, D. W. (2007). Design for additive manufacturing: A method to explore unexplored regions of the design space. In Eighteenth Annual Solid Freeform Fabrication Symposium, pp. 402-415. 